\title{
Involvement of lipogenesis in the lower VLDL secretion induced by oligofructose in rats
}

\author{
BY N. KOK ${ }^{1}$, M. ROBERFROID ${ }^{1}$, A. ROBERT ${ }^{2}$ AND N. DELZENNE ${ }^{1 *}$ \\ ${ }^{1}$ Unité de Biochimie Toxicologique et Cancérologique, Département des Sciences Pharmaceutiques, \\ Université Catholique de Louvain, BCTC 7369, Avenue Mounier 73, B-1200 Brussels, Belgium \\ ${ }^{2}$ Quantitative Methods in Health Sciences Section, Université Catholique de Louvain, Avenue \\ Hippocrate 55, Box 5550, B-1200 Brussels, Belgium
}

(Received 20 November 1995 - Revised 12 March 1996-Accepted 3 April 1996)

\begin{abstract}
Dietary supplementation with oligofructose (OFS; $100 \mathrm{~g} / \mathrm{kg}$ ), a non-digestible oligomer of $\beta$-D-fructose, decreases serum triacylglycerols in serum and VLDL of rats. In order to investigate the role of hepatic metabolism in the hypolipidaemic effect of OFS, male Wistar rats were fed on a standard diet with or without $100 \mathrm{~g}$ Raftilose $\mathrm{P}_{\mathrm{g}} / \mathrm{kg}$ as OFS source for $30 \mathrm{~d}$. OFS feeding (1) significantly decreased triacylglycerol and phospholipid concentrations in both blood and liver, (2) increased the glycerol-3phosphate liver content but decreased the hepatic activity of glycerol-3-phosphate acyltransferase (EC 2.3.1.15), suggesting a decrease in acylglycerol synthesis, (3) did not affect the blood non-esterified fatty acid concentrations, but (4) reduced by $54 \%$ the capacity of isolated hepatocytes to synthesize and secrete triacylglycerols from labelled acetate; the activity of fatty acid synthase, a key lipogenic enzyme was also significantly decreased. These findings suggest that OFS decreases serum triacylglycerols by reducing de novo fatty acid synthesis in the liver; the lower insulin level in the serum of OFS-fed rats could explain, at least partly, the metabolic effect induced by such non-digestible carbohydrates.
\end{abstract}

Fructans: Liver: Lipogenesis: Very-low-density lipoproteins

Many attempts have been made to control serum triacylglycerol (TAG) concentration by modifying dietary habits. Thus, the hypotriacylglycerolaemic effect of non-digestible but fermentable carbohydrates, including resistant starch or fructo-oligosaccharides, has been described both in human subjects (Glore et al. 1994) and in animals (Tokunaga et al. 1986; Vigne et al. 1987; Overton et al. 1994; de Deckere et al. 1995). The mechanism of their lowering effect on serum lipids still remains to be fully elucidated.

Feeding rats on a diet supplemented with oligofructose (OFS; $100 \mathrm{~g} / \mathrm{kg}$ ), a nondigestible but fermentable oligomer of $\beta$-D-fructose obtained by enzymic hydrolysis of chicory (Cichorium intybus) inulin, significantly lowers serum TAG and phospholipid (PL) concentrations (Delzenne et al. 1993). This is exclusively due to a decrease in the concentration of plasma VLDL (Fiordaliso et al. 1995). The hepatic synthesis of VLDL involves the biosynthesis of both lipids and apoproteins, their assembly into nascent VLDL particles, and the secretion of mature VLDL into the circulation (Gibbons, 1990).

Since newly-synthesized fatty acids are preferentially channelled into VLDL, the lipogenic activity of the liver is a key factor in hepatic VLDL-TAG output (Gibbons, 1990; Ribiero et al. 1991; Arbeeny et al. 1992; Park et al. 1992). Among the key enzymes that control lipogenesis, fatty acid synthase (FAS) is the most sensitive to nutrients and hormones (Boll et al. 1994). 
Fatty acid esterification is regulated at the reactions catalysed by glycerol-3-phosphate acyltransferase (EC 2.3.1.15; GPAT; Stals et al. 1994) and phosphatidate phosphohydrolase (EC 3.1.3.4; PAP; Sturton et al. 1978), but it also depends on the supply of the substrates, i.e. glycerol-3-phosphate (Declercq et al. 1982) and fatty acids; the availability of the latter depends on the balance between lipogenesis and $\beta$-oxidation, as well as on the serum concentration of non-esterified fatty acids (NEFA; Stals $e t$ al. 1994).

Hepatocytes isolated from OFS-fed rats have a lower capacity to esterify $\left[{ }^{14} \mathrm{C}\right]$ palmitate into TAG (Fiordaliso et al. 1995); this suggests that OFS lowers the hepatic output of VLDL by reducing the availability of esterified fatty acids. In order to test this hypothesis the enzyme activities involved in the control of fatty acid synthesis and esterification, as well as the concentration of rate-limiting substrates, were measured in OFS-fed rats.

In addition, insulin and glucose have been shown to be important effectors regulating fatty acid and TAG synthesis, both in vivo (Kaiser et al. 1983; Katsurada et al. 1990) and in vitro (Topping \& Mayes, 1972; Beynen et al. 1980; Spence \& Pitot, 1982; Giffhorn-Katz \& Katz, 1986). Non-digestible carbohydrates are known to modify the kinetics of absorption of carbohydrates, thus lowering glycaemia and insulinaemia (Stanley \& Newsholme, 1985; Ulrich, 1987; Leclère et al. 1994). Consequently, both variables were also measured in OFS-fed rats to test the hypothesis of a regulatory role for these factors in the modulation of hepatic lipid metabolism induced by oligofructose.

\section{MATERIALS AND METHODS}

\section{Chemicals}

Raftilose $P_{95}$ (Raffinerie Tirlemontoise, Tienen, Belgium), a mixture of glucosyl-

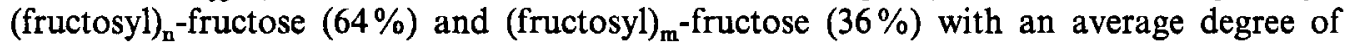
polymerization of $4 \cdot 8$, was used as OFS source.

$\left[1-{ }^{14} \mathrm{C}\right]$ acetic acid (specific activity $60 \mathrm{mCi} / \mathrm{mmol}$ ) was obtained from Amersham International Plc (Amersham, Bucks.). NA Beckman scintillation solution was obtained from Beckman (Geneva, Switzerland). Enzymes and coenzymes were purchased from Boehringer Mannheim (Mannheim, Germany). Fatty acid-free bovine serum albumin (fraction V; BSA) and all other chemicals were of the purest analytical grade available from Sigma Chemical Co. (St Louis, MO, USA).

\section{Maintenance of animals}

Thirty-two male Wistar rats ICOPS-WY IOPS from Iffa Credo (Les Oncins, France) weighing initially about $120 \mathrm{~g}$ were housed individually and maintained on a $12 \mathrm{~h}$ dark-12 h light alternating schedule (random design). Rats were randomly assigned to one of two groups. Control animals were fed ad libitum on a powdered basal diet obtained from a commercial source (UAR A04; UAR, Villemoisson-sur-Orge, France). OFS-fed rats received the same diet containing $100 \mathrm{~g}$ Raftilose $\mathrm{P}_{95} / \mathrm{kg}$.

On day 30, at 09.00 hours, corresponding to the postprandial period, twenty animals (ten control and ten OFS-fed rats) were anaesthetized with pentobarbital $(60 \mathrm{mg} / \mathrm{kg}$ body weight); blood was collected from the descending vena cava and the liver was excised and clamped immediately in liquid $\mathbf{N}_{2}$ for hepatic enzyme activity and metabolite concentration measurements.

\section{Analytical procedures}

Serum TAG, PL, total cholesterol, NEFA and glucose were measured using enzymic kits (Sopar-Biochem, Brussels, Belgium). Intra-assay CV were $2 \cdot 0,1 \cdot 7,0.9,2 \cdot 2$ and $1 \cdot 2$ respectively. The same kits were used for liver lipid analysis, after chloroform-methanol 
extraction according to Folch et al. (1957). Intra-assay CV were 5.2, 6.9 and $11.2 \%$ for liver TAG, PL and total cholesterol respectively.

Insulin concentrations were determined using a radioimmunoassay kit from Novo Nordisk (Bagsvaerd, Denmark). The intra-assay CV was 6.2.

The esterification pathway was assessed by measuring glycerol-3-phosphate hepatic content (Hohorst, 1965) and GPAT as well as $\mathrm{Mg}^{2+}$-dependent PAP activities (Bates \& Saggerson, 1977; Cheng \& Saggerson, 1978). The intra-assay CV was $12.4 \%$ for GPAT activity and $11.9 \%$ for PAP activity.

The availability of fatty acyl-S-CoA was assessed by measuring carnitine palmitoyltransferase (EC 2.3.1.21; CPT I; Schäfer et al. 1993) and fatty acid synthase (EC 2.3.1.38, EC 2.3.1.39, EC 2.3.1.41, EC 1.1.1.100, EC 4.2.1.58, EC 4.2.1.59, EC 1.3.1.10 and $E C$ 3.1.2.2; FAS) activities (Linn, 1981). Intra-assay CV were 6.9 and $6 \%$ for CPT I and FAS activities respectively.

Protein was assayed by the method of Lowry et al. (1951), using BSA, as the standard. All enzyme activities increased linearly with respect to protein concentration.

At the end of the 30 day feeding period, seven control and five OFS-fed rats were used for hepatocytes isolation. Liver perfusion was carried out under pentobarbital $(60 \mathrm{mg} / \mathrm{kg})$ anaesthesia at 10.00 hours. Hepatocytes were isolated according to the standard procedure described by Krack et al. (1980). The isolated cells were kept separately for each rat and incubated in one batch at a concentration of $1 \times 10^{6}$ cells $/ \mathrm{ml}$ with Krebs-bicarbonate buffer (pH 7.4) containing $10 \mathrm{~mm}$-glucose, $1 \mathrm{~mm}$-L-carnitine, fatty acid-free BSA $(10 \mathrm{~g} / \mathrm{l})$ and $2 \mathrm{~mm}-\left[1{ }^{14} \mathrm{C}\right]$ acetate $(0 \cdot 2 \mathrm{mCi} / \mathrm{mmol})$. Incubations were carried out at $37^{\circ}$ under an atmosphere of $\mathrm{O}_{2}-\mathrm{CO}_{2}(95: 5, \mathrm{v} / \mathrm{v})$ in a shaking water-bath.

At $30 \mathrm{~min}$ intervals, samples were removed from the suspension and cells were sedimented by centrifugation. TAG synthesis was measured by quantifying the incorporation of $\left[1-{ }^{14} \mathrm{C}\right]$ acetate into intra- and extracellular ${ }^{14} \mathrm{C}$-labelled TAG, as previously described by Deboyser et al. (1989). Total ${ }^{14} \mathrm{C}$-labelled TAG synthesis from labelled acetate was calculated as the sum of intra- and extracellular ${ }^{14} \mathrm{C}$-labelled TAG at $180 \mathrm{~min}$ of incubation.

\section{Statistical analysis}

Data were analysed (Fleiss, 1986) using BMDP New System Professional Edition statistical software (Statistical Solutions Inc., 1995). Serum and hepatic fatty acid metabolism data are reported as arithmetic means with their standard errors of the arithmetic mean. Variates were checked for outliers and for skewness in the control group and in the OFSfed group of rats. One outlier was observed in the OFS-fed group for the GPAT enzyme and this single outlier has been removed for computing robust significance levels. There was no skewed distribution. Therefore, variates were compared for variability between control and OFS-fed rats using the Levene F test with $P<0.01$ level for rejecting the equal variance assumption. The effect of OFS feeding on those variates was assessed at the two-sided $P<0.05$ level using either Student's $t$ test for equal variances or Student's $t$ test for unequal variances with the conservative choice of the minimum sample size minus one as degree of freedom. Labelled TAG data were analysed on a logarithmic scale because of a proportional relationship between means and standard deviations, but data are reported as geometric mean with the antilog of standard error of the logarithmic mean. ANOVA was performed for a three-factor design: (1) a between-groups factor with two levels for control and OFS-fed rats (the diet factor), (2) a within-groups factor with two levels for cellular and extracellular content (the localization factor), and (3) a repeated-measures factor with four unequal-spaced levels for $30,60,120$ and $180 \mathrm{~min}$ time-point measurements (the time factor). A Greenhouse-Geisser (GG) adjustment to the degree of freedom for tests of the 
repeated-measures factor was chosen because of significant sphericity tests $(P=\mathbf{0 . 0 3 5}$ for time error and $P<0.001$ for time $\times$ localization error) and non-decreasing correlation pattern as the time intervals increased. Despite significant linear $(P<0.001)$ and quadratic $(P<0.001)$ components in time-trend analysis, no significant interaction with diet was observed (GG $P=0.54)$ and there was a significant diet effect $(P=0.031)$. The secondorder interaction was borderline (GG $P=0.07$ ). Therefore, the effect of OFS feeding on labelled TAG data was assessed by submitting only the 180 min time-point measurements to a two-factor analysis of variance (the diet and the localization factor). The diet $\times$ localization interaction $P$ value was used to assess the effect of OFS feeding on the secretion of newly-synthesized TAG.

\section{RESULTS AND DISCUSSION}

The average daily feed intake was not significantly different between control rats $(23.5$ (SE 0.9) g/d) and OFS-fed rats $(24.1$ (SE 0.6) g/d); the average body weight at the end of the feeding period was 297 (SE 8) and 302 (SE 9) $\mathrm{g}$ for OFS-fed and control rats respectively.

Analysis of serum lipids (Table 1) confirmed that oral administration of OFS to rats significantly lowers serum TAG and PL concentrations by 40 and $18 \%$ respectively, without affecting total cholesterol level. These lipid-lowering effects are greater than those observed with other fermentable compounds such as guar gum which, at the same dose, decrease TAG levels by 15-20\% (Overton et al. 1994). TAG and PL contents are also lower in the liver of OFS-fed rats (Table 2). This latter observation supports the hypothesis that OFS decreases the liver capacity for fatty acid esterification. Three questions have been addressed in order to formulate new hypotheses with regard to the mechanism of action of OFS on hepatic lipid metabolism.

\section{Which are the effects of feeding oligofructose on key factors controlling acylglycerol synthesis in the liver?}

As OFS feeding not only lowers TAG but also PL, it could act on fatty acid esterification by modifying the activity of one of the enzymes that drive the esterification pathway, namely GPAT, which catalyses the first reaction of the pathway, or PAP, which converts phosphatidate to diacylglycerol, the common intermediate for PL and TAG biosynthesis (Bates \& Saggerson, 1977; Sturton et al. 1978; Stals et al. 1994). Results in Table 2 show that PAP activity was not affected by OFS feeding while GPAT activity was significantly lower in the liver of four OFS-fed rats compared with all control rats $(n 5)$. One OFS-fed rat had abnormally high GPAT activity and, therefore, was excluded from the statistical analysis. This suggests that OFS feeding could decrease fatty acid esterification, at least partly, through modulation of GPAT activity.

The extent of fatty acid esterification also depends on the availability of both substrates, glycerol-3-phosphate and fatty acyl-CoA. Declercq et al. (1982) have suggested that glycerol-3-phosphate is a limiting factor for fatty acid esterification in vivo for contents below 0.3 and $0.5 \mu \mathrm{mol} / \mathrm{g}$ in livers of fed and starved rats respectively. Results in Table 2 show that the hepatic glycerol-3-phosphate concentration exceeded that threshold in OFSfed rats and was even significantly higher than that in control rats. This relative increase in glycerol-3-phosphate liver content might be due to a decrease in its utilization for fatty acid esterification, as shown by the lower GPAT activity. These results are in line with our previous work in which we had shown that daily administration of OFS slightly but significantly reduced the hepatocyte capacity to esterify $\left[{ }^{14} \mathrm{C}\right]$ palmitate into TAG (Fiordaliso et al. 1995).

Fatty acid availability is considered as the rate-limiting factor for TAG synthesis under 
Table 1. Effect of feeding oligofructose (OFS) for $30 \mathrm{~d}$ on serum variables of rats $\dagger$ (Mean values with their standard errors for ten rats per dietary group)

\begin{tabular}{|c|c|c|c|c|}
\hline \multirow[t]{2}{*}{ Dietary group... } & \multicolumn{2}{|c|}{ Control } & \multicolumn{2}{|c|}{ OFS-fed } \\
\hline & Mean & SEM & Mean & SEM \\
\hline Triacylglycerols $(\mathrm{g} / \mathrm{l})$ & $1 \cdot 70$ & $0 \cdot 11$ & $1.04 * *$ & 0.09 \\
\hline Phospholipids (g/l) & 1.62 & 0.06 & $1 \cdot 35^{* *}$ & 0.05 \\
\hline Total cholesterol $(\mathrm{g} / \mathrm{l})$ & 0.68 & 0.04 & 0.65 & 0.04 \\
\hline Non-esterified fatty acids ( $\mathrm{g} / \mathrm{l})$ & 0.036 & 0.004 & 0.032 & 0.005 \\
\hline Glucose (mmol/l) & $10 \cdot 13$ & 0.38 & $8 \cdot 44^{* *}$ & 0.35 \\
\hline Insulin $(\mu \mathrm{g} / 1)$ & $5 \cdot 44$ & 0.49 & $3 \cdot 67^{*}$ & 0.49 \\
\hline
\end{tabular}

Mean values were significantly different from those for the control group (Student's $t$ test): ${ }^{*} P<0.05,{ }^{* *} P<$ 0.01 .

$\dagger$ For details of diets and procedures, see pp. 882-883.

Table 2. Effect of feeding oligofructose (OFS) for $30 \mathrm{~d}$ on hepatic fatty acid metabolism of rats $\dagger$

(Mean values with their standard errors for ten rats per dietary group except where indicated)

\begin{tabular}{|c|c|c|c|c|}
\hline \multirow[t]{2}{*}{ Dietary group... } & \multicolumn{2}{|c|}{ Control } & \multicolumn{2}{|c|}{ OFS-fed } \\
\hline & Mean & SEM & Mean & SEM \\
\hline \multicolumn{5}{|l|}{ Hepatic content (mg/g liver) } \\
\hline Triacylglycerols & 8.65 & 0.47 & $6.66^{*}$ & 0.55 \\
\hline Phospholipids & $16 \cdot 38$ & 0.26 & $14 \cdot 77^{* *}$ & $0 \cdot 29$ \\
\hline Total cholesterol & $2 \cdot 29$ & 0.04 & $2 \cdot 15$ & 0.08 \\
\hline Glycerol-3-phosphate ( $\mu \mathrm{mol} / \mathrm{g}$ liver $)$ & $0 \cdot 24$ & 0.01 & $0.38 * *$ & 0.04 \\
\hline \multicolumn{5}{|l|}{ Enzymes activities (mU/mg protein) } \\
\hline GPAT $\ddagger$ & 3.35 & 0.07 & $2 \cdot 98^{*}$ & 0.06 \\
\hline PAP & $5 \cdot 5$ & 0.4 & 4.9 & 0.53 \\
\hline CPT I & $24 \cdot 3$ & 1.8 & $22 \cdot 4$ & 1.4 \\
\hline FAS & $63-7$ & $4 \cdot 8$ & $37 \cdot 3 * *$ & 3.4 \\
\hline
\end{tabular}

GPAT, glycerol-3-phosphate acyltransferase (EC 2.3.1.15); PAP, phosphatidate phosphohydrolase (EC 3.1.3.4); CPT I, carnitine palmitoyltransferase I (EC 2.3.1.21); FAS, fatty acid synthase.

Mean values were significantly different from those for the control group (Student's $t$ test): *P<0.05, ** $P<$ 0.01 .

$\dagger$ All variables except GPAT were measured in freeze-clamped liver of ten control and ten OFS-fed rats. For details of diets and procedures see pp. 882-883.

$\$$ GPAT activity was measured in liver microsomes prepared from only five control and four OFS-fed rats.

physiological conditions (Stals et al. 1994); therefore, OFS could affect esterification either by increasing fatty acid catabolism, or by decreasing the hepatic fatty acid input.

The hypothesis of an increased fatty acid catabolism to explain a lower availability is unlikely: the activity of CPT I, the rate-limiting enzyme in the hepatic mitochondrial $\beta$ oxidation (MacGarry \& Foster, 1980), was not increased but even slightly decreased in the liver of OFS fed rats (Table 2). Moreover, we have previously shown that mitochondriaenriched fractions prepared from liver of OFS-fed rats had the same capacity to oxidize various fatty acids as those prepared from untreated rats (Kok et al. 1993).

Under our experimental conditions (Table 1) the plasma concentration of NEFA was not modified by OFS feeding. This result is in line with those of Sparks \& Sparks (1994) who 


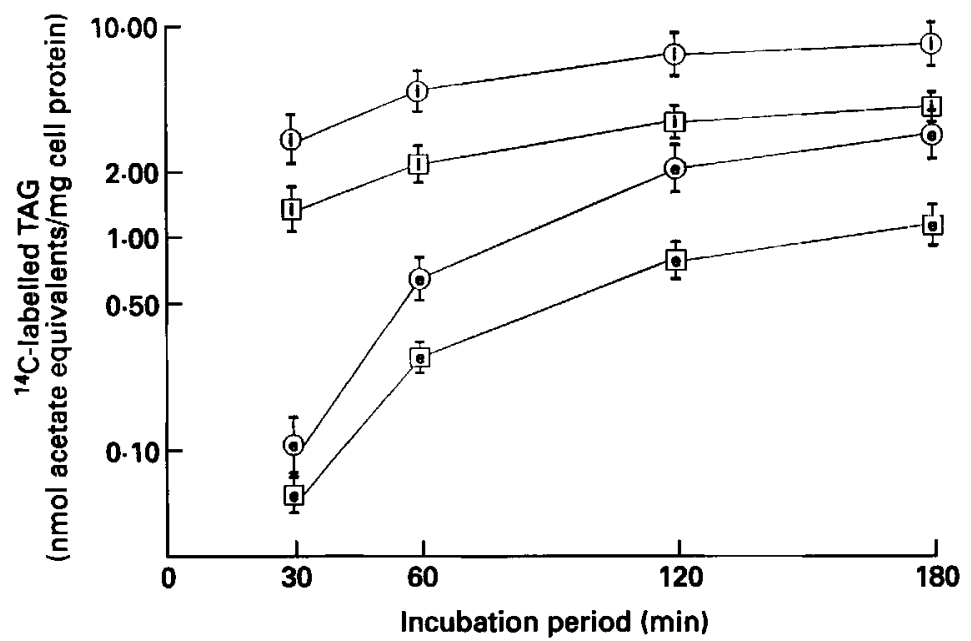

Fig. 1. Effect of feeding oligofructose (OFS) on triacylglycerol (TAG) synthesis from $\left[{ }^{14} \mathrm{C}\right]$ acetate. Hepatocytes from seven control $(O)$ and five OFS-fed rats $(\square)$ were incubated separately for $180 \mathrm{~min}$ in the presence of $2 \mathrm{mM}$ [1- $\left.{ }^{14} \mathrm{C}\right]$ acetate $(0.2 \mathrm{mCi} / \mathrm{mmol})$ and analysed. For details of procedures, see p. 883 . i, e, intracellular and extracellular (secreted) ${ }^{14} \mathrm{C}$-labelled TAG respectively. These data were analysed on a logarithmic scale because of a proportional relationship between means and standard deviations, but data are reported as geometric mean and antilog of standard error of the logarithmic mean, represented by vertical bars. A three-factor ANOVA, performed as described on pp. 882-883, showed a significant effect for OFS $(P=0.031)$. For details of diets, see p. 882.

suggested that the capacity for hepatic VLDL-TAG secretion relates to changes in lipogenic enzymes rather than to the availability of extracellular fatty acids.

Recent experimental data support a strong relationship between de novo fatty acid synthesis and VLDL secretion: in vivo, chronic treatments with modified starch or 5(tetradecyloxy)-2-furancarboxylic acid decrease acetyl-CoA carboxylase $(E C$ 6.4 .1 .2) and FAS activities in rats and hamsters respectively; this was correlated with a lower VLDLTAG secretion and a decrease in plasma TAG concentrations (Arbeeny et al. 1992; de Deckere et al. 1995).

Fatty acid synthesis is controlled by several key enzymes which are coordinately regulated when responding to physiological stimuli (Gibson et al. 1972); FAS activity is $40 \%$ lower in the liver of OFS-fed rats compared with controls (Table 2), thus suggesting that OFS feeding could decrease lipogenic flux and, thus, the liver VLDL-TAG secretion capacity (Gibbons, 1990; Arbeeny et al. 1992). Indeed, using an inhibitor of acetyl-CoA carboxylase, Arbeeny et al. (1992) demonstrated with primary cultures of hamster hepatocytes that when fatty acid synthesis from $\left[{ }^{14} \mathrm{C}\right]$ acetate is almost completely inhibited, VLDL-TAG secretion is decreased by $90 \%$.

Therefore, our results indicate that the lower TAG and PL formation in the liver of OFSfed rats could be due mostly to a decrease in de novo fatty acid synthesis. This hypothesis has been tested by raising the following question.

Is a reduced de novo lipogenic capacity of the liver involved in the triacylglycerol-lowering effect of oligofructose?

The time-course of ${ }^{14} \mathrm{C}$-labelled TAG synthesis and secretion from $\left[{ }^{14} \mathrm{C}\right]$ acetate was measured in hepatocytes isolated from control and OFS-fed rats (Fig. 1). The use of acetate as a lipogenic substrate is interesting because being activated by acetyl-CoA synthetase it bypasses not only the glycolytic pathway but also both the pyruvate dehydrogenase 
Table 3. Effect of feeding oligofructose (OFS) for $30 \mathrm{~d}$ on triacylglycerol synthesis from $\left[{ }^{14} \mathrm{C}\right]$ acetate in isolated rat hepatocytes*

(Mean values with their standard errors)

\begin{tabular}{|c|c|c|c|c|c|c|}
\hline \multirow[b]{3}{*}{ Dietary group ${ }^{\dagger}$} & \multicolumn{6}{|c|}{ TAG (nmol equiv. acetate/mg protein) } \\
\hline & \multicolumn{2}{|c|}{ Intracellular } & \multicolumn{2}{|c|}{ Extracellular } & \multicolumn{2}{|c|}{ Intracellular: extracellular } \\
\hline & Mean & SEM & Mean & SEM & Mean & SEM \\
\hline $\begin{array}{l}\text { Control rats }(n 7) \\
\text { OFS-fed rats }(n 5) \\
\text { Statistical significance } \\
\text { of differencef: } P=\end{array}$ & $\begin{array}{l}7 \cdot 72 \\
3 \cdot 91 \\
0 \cdot 041\end{array}$ & $\begin{array}{l}1.27 \\
1 \cdot 18\end{array}$ & $\begin{array}{l}2 \cdot 89 \\
1 \cdot 10 \\
0 \cdot 022\end{array}$ & $\begin{array}{l}1.29 \\
1.24\end{array}$ & $\begin{array}{l}2 \cdot 67 \\
3 \cdot 57 \\
0 \cdot 041\end{array}$ & $\begin{array}{l}1.25 \\
1.22\end{array}$ \\
\hline
\end{tabular}

* Hepatocytes were isolated from seven control and five OFS-fed rats, incubated separately for $180 \mathrm{~min}$ in the presence of $2 \mathrm{~mm}-\left[1-{ }^{14} \mathrm{C}\right]$ acetate $(0.2 \mathrm{mCi} / \mathrm{mmol})$ and analysed. For details of procedures, see p. 883 .

$\dagger$ For details of diets, see p. 882 .

¥ Two-factor ANOVA (the diet and the localization factors) was used to assess the effect of OFS feeding on the secretion of newly synthesized triacylglycerols after $180 \mathrm{~min}$.

(EC 1.2.4.1)-catalysed reaction and the transport from mitochondria into cytosol (Nishina \& Freeland, 1990).

OFS-feeding significantly reduces (by more than 2-fold) TAG synthesis and secretion from acetate in isolated hepatocytes (Fig. 1). After $180 \mathrm{~min}$ of incubation, total ${ }^{14} \mathrm{C}$-labelled TAG synthesis reached 10.65 (SE 1.27) and 5.02 (SE 1.19) nmol acetate equivalents/mg cell protein in the control and the OFS-fed group respectively. The parallelism between the extracellular and intracellular curves suggests that OFS feeding decreased the hepatocyte capacity for fatty synthesis and esterification through modulation of enzyme activity, as confirmed by the decreased activity of GPAT and FAS.

In the control group the newly-synthesized TAG secreted (extracellular) represented only $27.4 \%$ of the total synthesis, whereas $72.6 \%$ remained inside the hepatocyte (Table 3 ). These relative amounts were slightly but significantly modified in the OFS-fed group, in favour of cellular TAG, thus indicating that OFS feeding could also affect the VLDL-TAG secretion pathway.

These data thus support the hypothesis that a decreased de novo lipogenesis in the liver, through modulation of FAS activity, combined with a decrease in fatty acid esterification, causes a reduction in VLDL-TAG secretion in OFS-fed rats. A similar hypothesis has been proposed by Clark \& Jump (1994) who suggested that at least part of the hypotriacylglycerolaemic action of dietary polyunsaturated fats is due to the inhibition of hepatic de novo fatty acid synthesis.

This observation of a modulation of the hepatic de novo fatty acid and TAG synthesis in OFS-fed rats leaves open the question of its possible mechanism. The third question was raised in order to test one possible hypothesis.

\section{Are postprandial insulinaemia and glycaemia affected by oligofructose feeding?}

This question is probably relevant as dietary modulation of FAS activity is often linked to modifications of glucose and/or insulin serum levels: indeed, resistant starch decreases serum TAG concentration in rats (de Deckere et al. 1995), reduces FAS activity by 50 and $20 \%$ in adipose tissue and liver respectively, and concommitantly lowers postprandial insulin response by $30 \%$ without affecting glucose response (Takase et al. 1994). Similarly, 
acarbose, an intestinal glycosidase inhibitor which delays starch digestion, reduces glucose absorption and postprandial glycaemia and insulinaemia and also decreases FAS activity and mRNA concentration in the liver (Maury et al. 1993).

Our data show that OFS ingestion reduces postprandial glycaemia and insulinaemia by 17 and $26 \%$ respectively (Table 1 ). This could explain the lower activity of FAS, an enzyme whose transcription is primarily activated by glucose and insulin (Spence \& Pitot, 1982; Giffhorn-Katz \& Katz, 1986). In the same way, GPAT activity and transcription are also activated by insulin or a high-carbohydrate, fat-free diet (Bates \& Saggerson, 1977; Jerkins et al. 1995). This further confirms the hypothesis of a decreased level of insulin as a possible mediator of the hepatic effects of OFS.

Nevertheless, although the stimulatory action of insulin on hepatic lipogenesis and TAG synthesis is accepted generally in the literature, the direct effect of this hormone on hepatic VLDL secretion in vitro is often a matter for controversy. Early studies using rat liver perfusions or isolated hepatocytes suggested that insulin stimulated VLDL secretion (Topping \& Mayes, 1972; Beynen et al. 1979, 1980), whereas several more recent studies using human subjects (Lewis et al. 1995) or primary cultures of rat hepatocytes for periods up to $24 \mathrm{~h}$ demonstrated that this process was in fact inhibited by insulin (Björnsson $e t$ al. 1992). But this inhibitory effect is no longer present and there is even a stimulation if cells are incubated in the presence of insulin for $48 \mathrm{~h}$ (Duerden et al. 1989). It is possible that the effect of insulin on VLDL-TAG secretion is influenced by the prevailing hormonal and metabolic conditions within the hepatocyte at the time of preparation. This could explain the positive relationship between plasma insulin and total TAG and VLDL observed in chronic hyperinsulinaemia as well as in insulin-deficient states (Sparks \& Sparks, 1994). We could postulate, therefore, that the decrease in insulinaemia and glycaemia may contribute to the reduction in fatty acid and TAG synthesis and be part of the mechanism of the OFSinduced decrease in VLDL secretion by the liver, processes which are, as recently reviewed, strongly stimulated by insulin (Gibbons, 1990; Sparks \& Sparks, 1994).

However, other hypotheses cannot be ruled out and need to be tested. The level of TAG in the blood results from the balance between production of TAG-rich lipoproteins (TRL) and their utilization. Therefore, we cannot rule out the possibility that part of the hypotriacylglycerolaemic effect of OFS may be due to increased clearance of TRL. Insulin has a direct stimulatory effect on adipose tissue lipoprotein lipase (EC 3.1.1.34) activity (for review, see Braun \& Severson, 1992) and as feeding OFS decreases postprandial insulinaemia, we could postulate that the activity of the latter enzyme should be lower in OFS-fed rats. Further studies are needed to clarify the effect of feeding OFS on TRL catabolism and LPL activity.

We postulate that insulin modifications could, at least partly, explain the metabolic effect of OFS but other mediators could also be involved. In particular, OFS is largely fermented in the caeco-colon, leading to the production of short-chain carboxylic acids (Wang \& Gibson, 1993) and the portal concentrations of acetate and propionate are increased by more than twofold in OFS-fed rats (Delzenne \& Roberfroid, 1993). Since propionate has been reported to inhibit hepatic fatty acid synthesis (Nishina \& Freeland, 1990; Wright et al. 1990; Lin et al. 1995), further work is in progress to test the effect of this putative mediator on lipogenic enzyme activity and the VLDL-TAG secretion capacity of liver cells.

We wish to thank Dr P. Ferré for fruitful suggestions and discussions and Mrs V. Allaeys for skilled technical assistance. Raftilose ${ }^{\star} P_{95}$ was a gift from Raffineries Tirlemontoises, Tienen, Belgium. This work was supported by EEC grant no. AIR2-CT94-1095. 


\section{REFERENCES}

Arbeeny, C. M., Meyers, D. S., Bergquist, K. E. \& Gregg, R. E. (1992). Inhibition of fatty acid synthesis decreases very-low-density lipoprotein secretion in the hamster. Journal of Lipid Research 33, 843-851.

Bates, E. J. \& Saggerson, D. (1977). A selective decrease in mitochondrial glycerol phosphate acyltransferase activity in livers from streptozotocin-diabetic rats. FEBS Letters 64, 36-39.

Beynen, A., Vaartjes, W. \& Geelen, M. (1979). Opposite effects of insulin and glucagon in acute hormonal control of hepatic lipogenesis. Diabetes 28, 828-835.

Beynen, A., Vaartjes, W. \& Geelen, M. (1980). Acute effects of insulin on fatty acid metabolism in isolated hepatocytes. Hormone and Metabolic Research 12, 425-430.

Björnsson, O. J., Duerden, J. M., Bartlett, S. M., Sparks, J. D., Sparks, C. E. \& Gibbons, G. F. (1992). The role of pancreatic hormones in the regulation of lipid storage, oxidation and secretion in primary cultures of rat hepatocytes. Biochemical Journal 281, 381-386.

Boll, M., Weber, L. W., Stampfl, A. \& Messner, B. (1994). Lipogenic enzymes of rat liver and adipose tissue. Dietary variations and effect of polychlorinated biphenyls. Zeitschrift für Naturforschung 49C, 665-678.

Braun, J. \& Severson, D. L. (1992). Regulation of the synthesis, processing and translocation of lipoprotein lipase. Biochemical Journal 287, 337-347.

Cheng, C. \& Saggerson, E. (1978). Rapid antagonistic actions of noradrenaline and insulin on rat adipocyte phosphatidate phosphohydrolase activity. FEBS Letters 93, 120-124.

Clarke, S. D. \& Jump, D. B. (1994). Dietary polyunsaturated fatty acid regulation of gene transcription. Annual Review of Nutrition 14, 83-98.

Deboyser, D., Goethals, F., Krack, G. \& Roberfroid, M. (1989). Investigation into the mechanism of tetracyclineinduced steatosis: study in isolated hepatocytes. Toxicological and Applied Pharmacology 97, 473-479.

Declercq, P., Debeer, L. \& Mannaerts, G. (1982). Role of glycerol-3-phosphate and glycerophosphate acyltransferase in the nutritional control of hepatic triacylglycerol synthesis. Biochemical Journal 204, $247-256$.

de Deckere, E. A., Kloots, W. \& van Amelsvoort, J. M. (1995). Both raw and retrograded starch decrease serum triacylglycerol concentration and fat accretion in the rat. British Journal of Nutrition 73, 287-298.

Delzenne, N., Kok, N., Fiordaliso, M., Deboyser, D., Goethals, F. \& Roberfroid, M. (1993). Dietary fructooligosaccharides modify lipid metabolism in rats. American Journal of Clinical Nutrition $57,820 \mathrm{~S}$.

Delzenne, N. \& Roberfroid, M. (1994). Physiological effects of non digestible oligosaccharides. Food and Science Technology 27, 1-6.

Duerden, J. M., Bartlett, S. M. \& Gibbons, G. F. (1989). Long-term maintenance of high rates of very-lowdensity-lipoprotein secretion in hepatocyte cultures. Biochemical Journal 263, 937-943.

Fiordaliso, M., Kok, N., Desager, J. P., Goethals, F., Deboyser, D., Roberfroid, M. \& Delzenne, N. (1995). Oligofructose-supplemented diet lowers serum and VLDL concentrations of triglycerides, phospholipids and cholesterol in rats. Lipids 30, 163-167.

Fleiss, J. L. (1986). The Design and Analysis of Clinical Experiments. New York: John Wiley.

Folch, J., Lees, M. \& Sloane-Stanley, G. (1957). A simple method for the isolation and purification of total lipids from animal tissues. Journal of Biological Chemistry 226, 497-509.

Gibbons, G. F. (1990). Assembly and secretion of hepatic very-low-density lipoprotein. Biochemical Journal 268, 1-13.

Gibson, D. M., Lyons, R., Scott, D. \& Muto, Y. (1972). Synthesis and degradation of the lipogenic enzymes of rat liver. Advance in Enzyme Regulation 10, 187.

Giffhorn-Katz, S. \& Katz, N. R. (1986). Carbohydrate-dependent induction of fatty acid synthase in primary cultures of rat hepatocytes. European Journal of Biochemistry 159, 513-518.

Glore, S., Van Treeck, D., Knehans, A. \& Guild, M. (1994). Soluble fiber and serum lipids: a literature review. Journal of the American Dietary Association 94, 425-436.

Hohorst, H. J. (1965). L-(-)-glycerol-1-phosphate determination with glycerol-1-phosphate dehydrogenase. In Methods of Enzymatic Analysis, pp. 215-219 [H. U. Bergmeyer, editor]. New York and London: Academic Press.

Jerkins, A. A., Liu, W. R., Lee, S. \& Sul, H. S. (1995). Characterization of the murine mitochondrial glycerol-3phosphate acyltransferase promoter. Journal of Biological Chemistry 270, 1416-1421.

Kaiser, F. E., Schwartz, H. L., Mariash, C. N. \& Oppenheimer, J. H. (1983). Comparison of age-related decreases in the basal and carbohydrate inducible levels of lipogenic enzymes in adipose tissue and liver. Metabolism 32, 838-845.

Katsurada, A., Iritani, N., Fukuda, H., Matsumura, Y., Nishimoto, N., Nogushi, T. \& Tanaka, T. (1990). Effects of nutrients and hormones on transcriptional and post-transcriptional regulation of fatty acid synthase in rat liver. European Journal of Biochemistry 190, 427-433.

Kok, N., Fiordaliso, M., Delzenne, N., Deboyser, D., Goethals, F. \& Roberfroid, M. (1993). Role of liver metabolism in oligofructose-induced hypotriglyceridemia in rats. Archives Internationales de Physiologie, de Biochimie et de Biophysique 101, B15.

Krack, G., Gravier, O., Roberfroid, M. \& Mercier, M. (1980). Subcellular fractionation of isolated rat hepatocytes. A comparison with liver homogenate. Biochimica et Biophysica Acta 632, 619-629.

Leclère, C., Champ, M., Boillot, J., Guille, G., Lecannu, G., Molis, C., Bornet, F., Krempf, M., Delort-Laval, J. 
\& Galmiche, J. P. (1994). Role of viscose guar gum in lowering the glycemic response after a solid meal. American Journal of Clinical Nutrition 59, 914-915.

Lewis, G., Uffelman, K., Szeto, L., Weller, B. \& Steiner, G. (1995). Interaction between free fatty acids and insulin in the acute control of VLDL production in humans. Journal of Clinical Investigation 95, 158-166.

Lin, Y., Vonk, R. J., Slooff, M. J., Kuipers, F. \& Smit, M. J. (1995). Differences in propionate-induced inhibition of cholesterol and triacylglycerol synthesis between human and rat hepatocytes in primary culture. British Journal of Nutrition 74, 197-207.

Linn, T. (1981). Purification and crystallization of rat liver fatty acid synthetase. Archives of Biochemistry and Biophysics 209, 613-619.

Lowry, O., Rosebrough, N., Farr, A. \& Randall, A. (1951). Protein measurement with the folin phenol regent. Journal of Biological Chemistry 193, 265-273.

McGarry, J. \& Foster, D. (1980). Regulation of hepatic fatty acid oxidation and ketone body production. Annual Review of Biochemistry 49, 395-420.

Maury, J., Issad, T., Perdereau, D., Gouhot, B., Ferre, P. \& Girard, J. (1993). Effect of acarbose on glucose homeostasis, lipogenesis and lipogenic enzyme gene expression in adipose tissue of weaned rats. Diabetologia 36, 503-509.

Nishina, P. \& Freeland, R. (1990). Effects of propionate on lipid biosynthesis in isolated rat hepatocytes. Journal of Nutrition 120, 668-673.

Overton, P., Furlonger, N., Beety, J., Chakraborty, J., Tredger, J. \& Morgan, L. (1994). The effects of dietary sugar-beet fibre and guar gum on lipid metabolism in Wistar rats. British Journal of Nutrition 72, 385-395.

Park, O.-J., Cesar, D., Faix, D., Wu, K., Shackleton, C. H. \& Hellerstein, M. (1992). Mechanisms of fructoseinduced hypertriglyceridemia in the rat. Biochemical Journal 282, 753-757.

Ribiero, A., Mangenay, M., Cardot, P., Loriette, C., Chambaz, C., Rayssiguier, Y. \& Béréziat, G. (1991). Nutritional regulation of apolipoprotein genes: effect of dietary carbohydrates and fatty acids. Advances in Experimental Medicine and Biology 285, 407-416.

Schäfer, J., Turnbull, D. \& Reichmann, H. (1993). A rapid fluorometric method for the determination of carnitine palmitoyltransferase. Analytical Biochemistry 209, 53-56.

Sparks, J. D. \& Sparks, C. E. (1994). Insulin regulation of triacylglycerol-rich lipoprotein synthesis and secretion. Biochimica et Biophysica Acta 1215, 9-32.

Spence, J. \& Pitot, H. (1982). Induction of lipogenic enzymes in primary cultures of rat hepatocytes. Relationship between lipogenesis and carbohydrate metabolism. European Journal of Biochemistry 128, 15-20.

Stals, H. K., Top, W. \& Declercq, P. (1994). Regulation of triacylglycerol synthesis in permeabilized rat hepatocytes. Role of fatty acid concentration and diacylglycerol acyltransferase. FEBS Letters 343, 99-102.

Stanley, J. C. \& Newsholme, E. A. (1985). The effect of dietary guar gum on the activities of some key enzymes of carbohydrate and lipid metabolism in mouse liver. British Journal of Nutrition 53, 215-222.

Statistical Solutions Inc. (1995). BMDP New System Professional Edition. Berkeley, CA: University of California Press.

Sturton, R. G., Pritchard, P. H., Han, L. Y. \& Brindley, D. N. (1978). The involvement of phosphatidate phosphorylase and phospholipase A activities in the control of hepatic glycerolipid synthesis. Effects of acute feeding with glucose, fructose, sorbitol, glycerol and ethanol. Biochemical Journal 174, 667-670.

Takase, S., Goda, T. \& Watanabe, M. (1994). Monostearoylglycerol-starch complex: its digestibility and effects on glycemic and lipogenic responses. Journal of Nutrition Science and Vitaminology 40, 23-36.

Tokunaga, T., Oku, T. \& Hosoya, N. (1986). Influence of chronic intake of a new sweetener fructooligosaccharide (Neosugar) on growth and gastrointestinal function of the rat. Journal of Nutrition Science and Vitaminology 32, 111-121.

Topping, D. L. \& Mayes, P. A. (1972). The immediate effects of insulin and fructose on the metabolism of the perfused liver. Changes in lipoprotein secretion, fatty acid oxidation and esterification, lipogenesis and carbohydrate metabolism. Biochemical Journal 126, 295-311.

Ulrich, I. H. (1987). Evaluation of a high-fiber diet in hyperlipidemia: a review. Journal of the American College of Nutrition 6, 19-25.

Vigne, J. L., Lairon, D., Borel, P., Portugal, H., Pauli, A. M., Hauton, J. C. \& Lafont, H. (1987). Effect of pectin, wheat bran and cellulose on serum lipids and lipoproteins in rats fed on a low- or high-fat diet. British Journal of Nutrition 58, 405-413.

Wang, X. \& Gibson, G. (1993). Effects of the in vitro fermentation of oligofructose and inulin by bacteria growing in the human large intestine. Journal of Applied Bacteriology 75, 373-380.

Wright, R. S., Anderson, J. W. \& Briges, S. R. (1990). Propionate inhibits hepatocyte lipids synthesis. Proceedings of the Society for Experimental Biology and Medicine 195, 26-29. 